\title{
An Empirical Study on the Organizational Motivation and the Related Factors of "Post-80s" Employees
}

\author{
Dongjin Yang, Chaoyang Feng \\ Management School, Jinan University, Guangzhou, China \\ Email: yang.dongjin@163.com
}

Received 7 October 2015; accepted 21 November 2015; published 24 November 2015

Copyright $@ 2015$ by authors and Scientific Research Publishing Inc.

This work is licensed under the Creative Commons Attribution International License (CC BY).

http://creativecommons.org/licenses/by/4.0/

(c) (i) Open Access

\section{Abstract}

A research model for the organizational motivation and outcome variables of the "Post-80s" is established in this article for large-sample survey. Through Exploratory Factor Analysis and Confirmatory Factor Analysis, the author has discovered that the organizational motivation of the "Post80s" is comprised of five dimensions including career development, salary and benefits, leadership characteristics, institutional environment and colleague relationships; the perception of organizational motivation has a positive impact on job satisfaction, organizational commitment and employee engagement and a negative impact on turnover intention; and job satisfaction is the complete mediation between the perception of organizational motivation and turnover intention, while organizational commitment is the complete mediation between the perception of organizational motivation and employee engagement. In the end, countermeasures for the motivation of the "Post-80s" are put forward in this article.

\section{Keywords}

“Post-80s", Organizational Motivation, Motivators

\section{Introduction}

The "Post-80s" employees are employees that born after 1980. The "Post-80s" are getting more sophisticated with the development of market economy, science, the Internet and globalization. They are characterized by a strong sense of independence, pragmatic and pluralistic values as well as broad visions [1]. And the "Post-80s" are the link between the employees of various ages [1] due to the distinctive culture and values engraved in their mind [2]. 
The study of Fudan University and Adfaith Management Consulting Inc. in 2012 shows that the turnover rate of the "Post-80s" is 10\% higher than the average; the survey of IBM and N-Dynamic Market Research \& Consultancy Limited in 2011 suggests that the "Post-80s" are generally less satisfied with their job compared with the previous generation. Organizational managers may find it difficult to understand what the "younger generation" has in mind. Therefore, it is urgent that the motivating requirements of the "Post-80s" are explored to figure out the difference between the organizational motivation highly valued by the "Post-80s" and the traditional motivation theory and then develop nichetargeting motivation strategies for the employees. Formal research on the "Post-80s" in the academia circle begins from 2006, and can be classified into sociological perspective and management perspective based on the discipline. The former is mainly focused on the upbringing background and personalities [3] of the "Post-80s" as well as the difference between the "Post-80s" and the previous generations, whereas the latter is more about the occupational characteristics, motivating requirements and applicable management strategies [4] of the "Post-80s". The emphases of existing studies are different though they have covered most of the issues related to the "Post-80s", and the analysis of the motivating requirements of the "Post-80s" from the organizational perspective is insufficient and the potential of systematic and quantitative research remains huge. This research sets to help enterprise managers to understand the organizational motivating requirements of the "Post-80s" employees and put forward strategic recommendations on that matter. Three questions are discussed in this article: What factors and dimensions are included in the organizational motivation to the satisfaction of the "Post-80s" employees? What influence will the perception of organizational motivation exert on the psychology and behavior of the "Post-80s" employees? What measures should be taken by enterprise managers to effectively motivate the "Post-80s" employees?

\section{Theoretical Analysis and Research Hypothesis}

Organizational motivation is defined from two perspectives: process-oriented and content-oriented. The former holds that organizational motivation represents a process in which the various behavioral agents within the organization exchange for the contribution of other agents through inducements in order to realize their own objectives; while the latter believes that organizational motivation stands for the material and spiritual motivation provided to organization members by the rules and executives of the organization [5] [6]. This study is based on organizational motivation from the content-oriented perspective. The author is convinced that organizational motivation is the integration of tangible and intangible motivative factors that can motivate, maintain and regulate employee behavior and deliver employee targets [7]. And "organizational motivation” is a subcategory of "motivation”, therefore the existing theories on motivation and research findings are still applicable to organizational motivation.

Seen from the existing research findings, two-factor theory claims that the organization provides motivation and hygienic factors and that high-level motivation comes from job-related motivative factors [8]-[11]; Robbins considered job with a certain degree of challenge, fair pay, supportive working environment, harmonious relationship among colleagues and the correlation between individual personality and job requirements, ect as the indispensible elements of motivation expected by the employee [12]; Adams specified the significance of performance evaluation standards and organizational fairness in his Equity Theory; Yao Ji (2009) pointed out that the motivative factors much valued by the "Post-80s" can be divided into work value, personal development and institutional environment [13]; Hou Chengyi and Wang Zhouwei (2011) classified organizational motivation into five dimensions, namely salary and benefits, decision latitude, personal development, working environment and job achievement [14]. And the author puts forward the following hypothesis:

Hypothesis 1: Organizational motivation has a multi-dimensional structure and manifests the overall level of multiple factors.

Organizational motivation is not static [15], and the employees' perception of motivation differs in accordance with the specific social environment and historical background. Accordingly, the unique personality of the "Post-80s" formed in special upbringing background becomes evident in the judgment of organizational motivative factors.

Hypothesis 2: Organizational motivation of the "Post-80s" employees includes specific motivative factors reflecting their personalities.

In recent years, scholars believe that the mentality and behavior of organizational commitment, loyalty, employee engagement, retention intention and turnover intention reflects the influence of various factors within the 
organization. The author believes that the employees' perception of organizational motivation is the most direct assessment of relevant factors within the organization, and such assessment will definitely affect the mentality and behavior of the employees. Therefore, job satisfaction, organizational commitment, employee engagement and turnover intention are taken as variables to measure the consequence of the "Post-80s" employees' perception of organizational motivation.

The author has made the following analysis of the impact of perception of organizational motivation on outcome variables: firstly, the impact of perception of organizational motivation on job satisfaction. The "Job Descriptive Index (JDI)” Scale compiled by Smith, Kendall and Hulin in 1969 is one of the most widely employed evaluation system. The evaluation of job satisfaction includes the employees' views on the job, relations with their superiors and colleagues, promotion policy and salary and benefits. It is obvious that organizational motivation has heavy weight in employees' evaluation of overall job satisfaction, and that the employees will be more satisfied with their job if they think highly of the organizational motivation; secondly, the impact of the perception of organizational motivation on organizational commitment. According to Meyer and Allen, there are three components of organizational commitment, namely affective commitment, continuance commitment and normative commitment. Normative commitment refers to the employees' reception of the rules and regulations and codes of conduct of the organization, and affective commitment refers to the employees' positive emotional to the organization. Normative commitment and affective commitment are two indispensible component of organizational commitment, and the employees’ organizational commitment will be affected by their evaluation of partial component of organizational motivation; thirdly, the impact of the perception of organizational commitment on employee engagement. Employee engagement refers to the extend to which the employees are committed to their work both physically and psychologically, and the engagement relies on the satisfaction, mainly organizational motivation, they gained from their job. The more motivation the employees perceive, the better they will get engaged in their job; and lastly, the impact of the perception of organizational motivation on turnover intention. Motivation is key to all the fundamental issues of human resource management, while employee turnover is but a manifestation of the issues concerning human resource management. It has been widely accepted by managers and scholars that employee turnover is resulted from insufficient motivation. It is assumed that:

Hypothesis 3a: The perception of organization motivation has a positive impact on job satisfaction;

Hypothesis 3b: The perception of organization motivation has a positive impact on organizational commitment;

Hypothesis 3c: The perception of organization motivation has a positive impact on employee engagement;

Hypothesis 3d: The perception of organization motivation has a negative impact on employee turnover intention.

There is a special phenomenon in the performance of the "Post-80s" employees that those who are enthusiastic and well-performed in their work tend to resign without any sign, which means that their engagement does not necessarily result in the intention to stay. Apparently, the perception of organizational motivation does have an influence on employee engagement and turnover intention, while it is not the only influencing factor and its influence may be undermined by other mediators. On the one hand, the "Post-80s" employees' perception of organizational motivation does have an effect on their evaluation of job satisfaction which further leads to high turnover rate; on the other hand, organizational commitment and employee engagement is inter-linked as the higher the employees' perception of organizational motivation is, the better committed they will be to their organization. It is assumed that:

Hypothesis 4a: Job satisfaction plays the intermediary role between the employees’ perception of organizational motivation and turnover intention;

Hypothesis 4b: Organizational commitment plays the intermediary role between the employees’ perception of organizational motivation and engagement.

\section{Research Design}

\subsection{Research Samples}

In order to guarantee the sample recovery rate, the validity and the representative, first, selected the companies that the authors' students or classmates being employed. Secondly, the selected companies must be located in different provinces of different economic development level. Ultimately, the samples are from 10 companies, 3 
in Guangdong, 2 in Zhejiang, 3 in Henan and 2 in Jiangsu Province. These 10 companies come from different industry, 3 from manufacturing, 1 from construction, 1 from transportation, 2 from catering industry, 1 from information technology services, 1 from financial sector, 1 from real estate. In each phase of the survey, questionnaires were distributed on average. The organizational motivators are studied 51 valid copies of open-ended questionnaires, 307 valid copies of pretest questionnaires and 449 valid copies of formal questionnaires. And 230 copies of the formal questionnaires are taken for Exploratory Factor Analysis and the remaining 219 copies are used for Confirmatory Factor Analysis. Furthermore, a total of 292 copies of valid questionnaires are employed to analyze the impact of the perception of organizational motivation on outcome variables.

\subsection{Measurement of Variables}

The measurement index of the perception of organizational motivation comes from the gained from the factor analysis. And the measurement index of outcome variables, job satisfaction and organizational commitment in this case, comes from the Overall Job Satisfaction Scales of Brayfield and Rothe and the Organizational Commitment Scale of Ling Wenquan et al. [16]. The author selected five heavy-loaded questions for each dimension in the original scale and finally retained four of the five questions according to the results of Principal Component Analysis ${ }^{1}$; The measurement index of employee engagement is selected from the Employee Engagement Scale of Huo Yuanyuan [17]. The author picked out one question for each of the three dimensions and got three questions ${ }^{2}$. The measurement index of turnover intention is taken from the scales of Cammann, Fichman, Jenkins and Klesh. The author took out two of the three questions ${ }^{3}$. Test results of the reliability and validity of scales for outcome variables are shown in Table 1.

\subsection{Research Methodology}

Factor analysis includes Exploratory Factor Analysis (EFA) and Confirmatory Factor Analysis (CFA). SPSS17.0 and Amos7.0. are adopted in this study, and the latter is employed to analyze the relationship between organizational motivation and outcome variables by constructing a structural equation model and testing and modifying the fitness of the model.

\section{Empirical Analysis and the Results}

\subsection{Measurement of the Dimensions of Organizational Motivation}

1) Exploratory Factor Analysis. Through the factor analysis and screening of the forty questions in formal questionnaire, the author finally got five factors, each containing three questions with a total of fifteen questions. The total variance explanation is $70.249 \%$, the KMO value of the last principal component analysis is 0.786 , the chi-square value of Bartlett Sphericity Test is 1294.569 and the degree of freedom has reached a significant 105, indicating that the sample is suitable for factor analysis. The naming, question item and loading of each factor is specified in Table 2.

2) Confirmatory Factor Analysis. Confined by length, only four models with good fitness are discussed in this article. And the major fit indexes of the four models are listed in Table 3. Obviously, the fit index of Model 2 is most optimal compared with that of the other three presumptive models, which makes Model 2 the most applicable presumptive model. Hypothesis 1 has been verified as the organizational motivation of the "Post-80s" employees is comprised of five relatively stable dimensions. The fifteen factors of organizational motivation include

Table 1. Test results of the reliability and validity of scales for outcome variables $(\mathrm{N}=292)$.

\begin{tabular}{ccccc}
\hline Scale & Job satisfaction & Organizational commitment & Employee engagement & Turnover intention \\
\hline$\alpha$ coefficient & - & 0.921 & 0.863 & 0.937 \\
$\begin{array}{c}\text { Variance contribution ratio of the } \\
\text { principle component (\%) }\end{array}$ & - & $81.051 \%$ & $78.526 \%$ & $94.103 \%$ \\
\hline
\end{tabular}

${ }^{1}$ I am deeply attached to my company; I feel obliged to get fully committed to my work; My current job offers a promising future as I can adapt what I have learned to my work; I will suffer great loss if I leave my company at the moment.

${ }^{2}$ I am passionate about my work; I try my best to do a good job; and I am fully engaged when I am doing my work.

${ }^{3}$ I intend to find another job recently; and I will accept the new position if it is suitable for me. 
Table 2. The naming, question item and loading of each factor $(\mathrm{N}=230)$.

\begin{tabular}{|c|c|c|c|c|}
\hline Leadership characteristics & Institutional environment & Career development & Salary and benefits & $\begin{array}{l}\text { Colleague } \\
\text { relationship }\end{array}$ \\
\hline $\begin{array}{c}\text { Leadership } \\
\text { capability } 0.804\end{array}$ & $\begin{array}{c}\text { Fair reward } \\
\text { and penalty } 0.824\end{array}$ & Promotion 0.891 & $\begin{array}{l}\text { Appreciation and } \\
\text { reward } 0.838\end{array}$ & $\begin{array}{c}\text { Cooperation and } \\
\text { coordination } 0.859\end{array}$ \\
\hline $\begin{array}{l}\text { Leaders' recognition and } \\
\text { appreciation } 0.789\end{array}$ & $\begin{array}{c}\text { Complete system } \\
0.817\end{array}$ & $\begin{array}{c}\text { Training } \\
\text { opportunity } 0.799\end{array}$ & Holidays 0.778 & $\begin{array}{c}\text { Relationship and } \\
\text { atmosphere } 0.824\end{array}$ \\
\hline $\begin{array}{c}\text { Leaders' support } \\
\text { and guidance } 0.759\end{array}$ & Fair pay 0.679 & Salary raise 0.787 & $\begin{array}{l}\text { Salary and benefits } \\
0.749\end{array}$ & $\begin{array}{c}\text { Mutual respect } \\
0.587\end{array}$ \\
\hline
\end{tabular}

Table 3. Major fit index of four presumptive models $(\mathrm{N}=219)$.

\begin{tabular}{|c|c|c|c|c|c|c|c|c|c|c|}
\hline \multirow{2}{*}{ Fit index } & \multicolumn{5}{|c|}{ Absolute fit index } & \multicolumn{2}{|c|}{ Comparative fit index } & \multicolumn{3}{|c|}{ Substitutive indicator } \\
\hline & CMIN & DF & CMIN/DF & RMR & GFI & NFI & PNFI & NCP & RMSEA & CFI \\
\hline Model $1^{1}$ & 144.136 & 80 & 1.802 & 0.045 & 0.918 & 0.878 & 0.669 & 64.136 & 0.061 & 0.940 \\
\hline Model $2^{2}$ & 126.890 & 79 & 1.606 & 0.042 & 0.926 & 0.896 & 0.674 & 47.890 & 0.053 & 0.957 \\
\hline Model $3^{3}$ & 135.222 & 84 & 1.610 & 0.045 & 0.920 & 0.890 & 0.712 & 51.222 & 0.053 & 0.954 \\
\hline Model $4^{4}$ & 137.018 & 83 & 1.651 & 0.043 & 0.921 & 0.886 & 0.700 & 54.018 & 0.055 & 0.951 \\
\hline Optimal value & Minimum & - & $<2$ & $<0.5$ & $>0.9$ & $>0.9$ & $>0.5$ & Minimum & $<0.1$ & $>0.9$ \\
\hline
\end{tabular}

${ }^{1}$ The first-order 5-factor model is the initial model obtained from the Confirmatory Factor Analysis. ${ }^{2}$ The first-order 5 -factor model is the modified Model of Model 1, two-way covariance is added to the residual variables of "exceptional salary and benefits" (salary and benefits) and "harmonious colleague relationship" (colleague relationship). Its practical significance can be that the harmonious relationship between colleagues constitutes the non-economic benefits enjoyed by the employees. The correlation is objective and well-grounded, and is also manifested in the subsequent models. ${ }^{3}$ The second-order single-factor model is a second-order "organizational motivation" structure developed through the combination of five factors on the basis of the first-order 5-factor modified model. "The second-order 2-factor model is a second-order "direct motivation" structure formed by the integration of career development and salary and benefits, and another second-order "direct motivation" structure formed by the integration of colleague relationship, leadership characteristics and institutional environment.

mutual respect, harmonious interpersonal relationship, holidays and fairness which are closely related to the characteristics of the "Post-80s", therefore Model has also been verified.

3) Reliability Test. A test is conducted to verify the internal consistency of the subscales (factor level) and scales, the results of which are listed in Table 4 . The $\alpha$ coefficient of each subscale is above 0.70 and the $\alpha$ coefficient of the overall questionnaire is 0.833 , indicating good reliability of measuring results.

\subsection{Impact of the Perception of Organizational Motivation on Employees' Psychological and Behavioral Variables}

1) Analysis of the impact of the perception of organizational motivation on job satisfaction, organizational commitment, employee engagement and turnover intention. An assumptive model (see Figure 1) is constructed on the basis of Hypothesis 3a, 3b, 3c and 3d. By applying Amos to the assumptive model, the Model Standardized Coefficients of the perception of organizational motivation F6 $\rightarrow$ job satisfaction F7, the perception of organizational motivation F6 $\rightarrow$ organizational commitment F8, the perception of organizational motivation F6 $\rightarrow$ employee engagement F9, the perception of organizational motivation F6 $\rightarrow$ turnover intention F10 are $0.95,0.93,0.72$ and -0.90 respectively, all of which are quite significant concerning the 0.001 value. Therefore, the perception of organizational motivation has a significant positive impact on job satisfaction, organizational commitment and employee engagement and a significant negative impact on turnover intention. The Hypothesis 3a, 3b, 3c and 3d are verified.

2) Analysis of the intermediary role of job satisfaction between the perception of organizational motivation and turnover intention. Baron and Kenny's methods is adopted for the test and analysis of mediators [18]. The analysis results are listed in Table 5. Model E1 has good fitting effect (see Table 6). And the results show that job satisfaction serves as the complete mediation between the perception of organizational motivation and turnover intention, and Hypothesis 4a has been verified. 
Table 4. Result of reliability test $(\mathrm{N}=219)$.

\begin{tabular}{ccccccc}
\hline Sub-scale & $\begin{array}{c}\text { Career } \\
\text { development }\end{array}$ & $\begin{array}{c}\text { Salary and } \\
\text { benefits }\end{array}$ & $\begin{array}{c}\text { Leadership } \\
\text { characteristics }\end{array}$ & $\begin{array}{c}\text { Colleague } \\
\text { relationship }\end{array}$ & $\begin{array}{c}\text { Institutional } \\
\text { environment }\end{array}$ & Scale \\
\hline$\alpha$ coefficient & 0.778 & 0.737 & 0.796 & 0.776 & 0.776 & 0.833 \\
\hline
\end{tabular}

Table 5. Analysis process and results of the intermediary role of job satisfaction between organizational motivation and turnover intention $(\mathrm{N}=292)$.

\begin{tabular}{|c|c|c|c|c|}
\hline Model & Diagram & Path & $\begin{array}{l}\text { Standardized path } \\
\text { coefficient (p) }\end{array}$ & $\begin{array}{l}\text { Significance } \\
\text { probability }\end{array}$ \\
\hline A1 & $\stackrel{F 6}{\longrightarrow} \longrightarrow$ & $\begin{array}{l}\text { Perception of Organizational Motivation F6 } \rightarrow \text { Job Satisfaction } \\
\text { F7 }\end{array}$ & 0.95 & $* * *$ \\
\hline B1 & (F6)- & $\begin{array}{l}\text { Perception of Organizational Motivation F6 } \rightarrow \text { Turnover } \\
\text { Intention F10 }\end{array}$ & -0.90 & $* * *$ \\
\hline $\mathrm{C} 1$ & (F7) $\longrightarrow$ F10 & Job Satisfaction F7 $\rightarrow$ Turnover Intention F10 & -0.88 & *** \\
\hline \multirow{3}{*}{ D1 } & \multirow{3}{*}{ 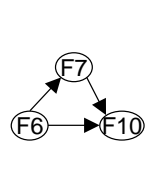 } & $\begin{array}{l}\text { Perception of Organizational Motivation F6 } \rightarrow \text { Turnover } \\
\text { Intention F10 }\end{array}$ & -0.42 & 0.096 \\
\hline & & $\begin{array}{l}\text { Perception of Organizational Motivation F6 } \rightarrow \text { Job Satisfaction } \\
\text { F7 }\end{array}$ & 0.94 & *** \\
\hline & & Job Satisfaction F7 $\rightarrow$ Turnover Intention F10 & -0.48 & 0.046 \\
\hline \multirow{2}{*}{ E1 } & & $\begin{array}{l}\text { Perception of Organizational Motivation F6 } \rightarrow \text { Job Satisfaction } \\
\text { F7 }\end{array}$ & 0.94 & *** \\
\hline & (F6) & Job Satisfaction F7 $\rightarrow$ Turnover Intention F10 & -0.88 & *** \\
\hline
\end{tabular}

Note: ${ }^{* * *} \mathrm{p}<0.001$, similar hereinafter.

Table 6. Major fit index of model E1 ( $\mathrm{N}=292)$.

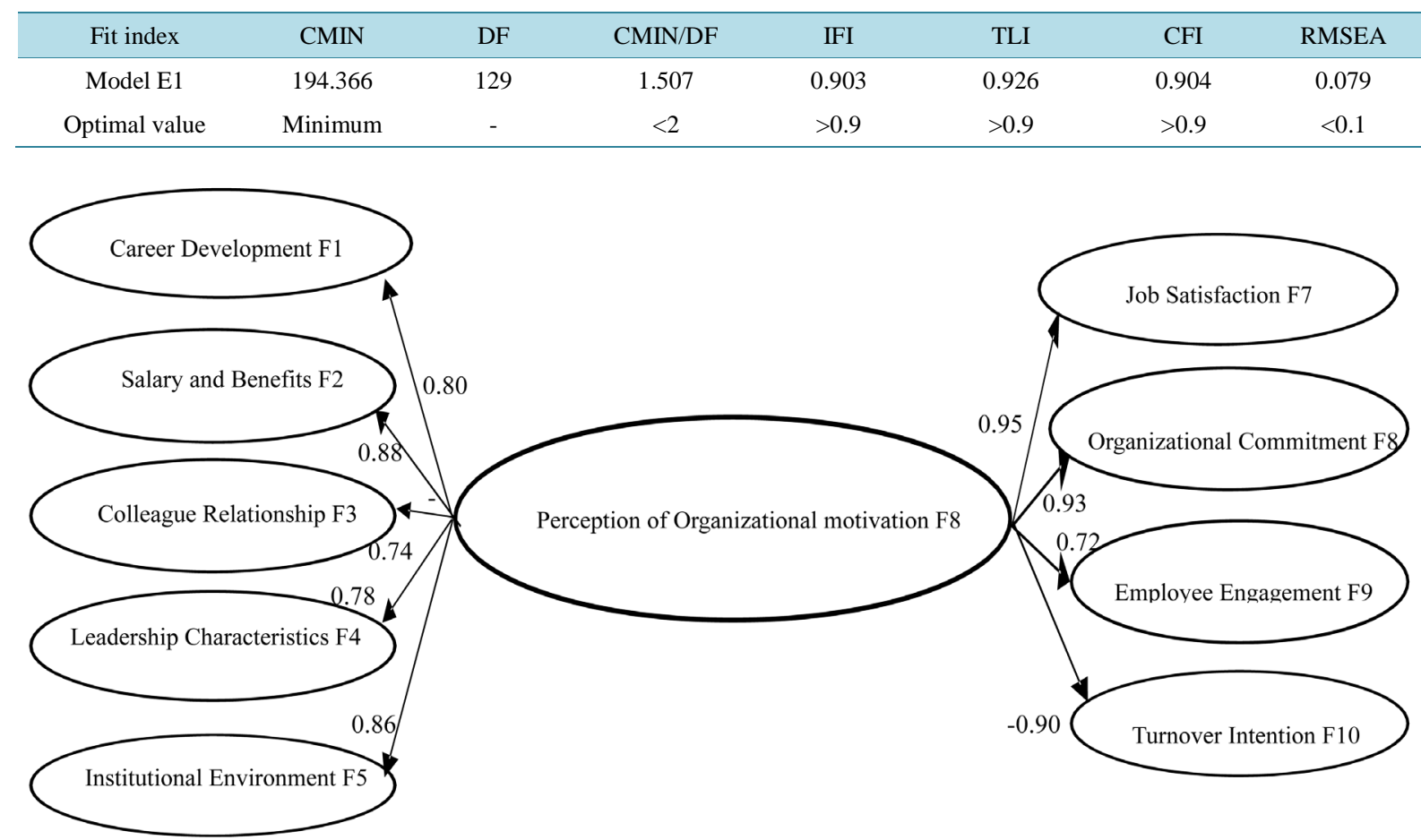

Figure 1. Interactive model of organizational motivation on outcome variables.

3) Analysis of the intermediary role of organizational commitment between the perception of organizational motivation and employee engagement. The analysis results are listed in Table 7. The fitting effect of Model E2 is desirable (see Table 8). The results show that organizational commitment works as complete mediation between perception of organizational motivation and employee engagement, and Hypothesis $4 \mathrm{~b}$ has been verified. 
Table 7. Analysis process and results of the intermediary role of organizational commitment between organizational motivation and employee engagement $(\mathrm{N}=292)$.

\begin{tabular}{|c|c|c|c|c|}
\hline Model & Diagram & Path & $\begin{array}{l}\text { Standardized path } \\
\text { coefficient (p) }\end{array}$ & $\begin{array}{l}\text { Significance } \\
\text { probability }\end{array}$ \\
\hline A2 & $\stackrel{\mathrm{FG}}{\longrightarrow} \longrightarrow \mathrm{F8}$ & $\begin{array}{l}\text { Perception of Organizational Motivation F6 } \rightarrow \text { Organizational } \\
\text { Commitment F8 }\end{array}$ & 0.93 & *** \\
\hline B2 & $\stackrel{F 6}{\longrightarrow} \longrightarrow$ & $\begin{array}{l}\text { Perception of Organizational Motivation F6 } \rightarrow \text { Employee } \\
\text { Engagement F9 }\end{array}$ & 0.72 & *** \\
\hline C2 & 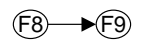 & Organizational Commitment F8 $\rightarrow$ Employee Engagement F9 & 0.76 & $* * *$ \\
\hline \multirow{3}{*}{ D2 } & \multirow{3}{*}{ 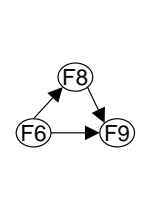 } & $\begin{array}{l}\text { Perception of Organizational Motivation F6 } \rightarrow \text { Employee } \\
\text { Engagement F9 }\end{array}$ & 0.10 & 0.701 \\
\hline & & $\begin{array}{l}\text { Perception of Organizational Motivation F6 } \rightarrow \text { Organizational } \\
\text { Commitment F8 }\end{array}$ & 0.90 & $* * *$ \\
\hline & & Organizational Commitment F8 $\rightarrow$ Employee Engagement F9 & 0.67 & 0.008 \\
\hline \multirow[t]{2}{*}{ E2 } & & $\begin{array}{l}\text { Perception of Organizational Motivation F6 } \rightarrow \text { Organizational } \\
\text { Commitment F8 }\end{array}$ & 0.90 & $* * *$ \\
\hline & & Organizational Commitment F8 $\rightarrow$ Employee Engagement F9 & 0.77 & ${ }^{* * *}$ \\
\hline
\end{tabular}

Table 8. Major fit index of model E2 ( $\mathrm{N}=292)$.

\begin{tabular}{cccccccc}
\hline Fit index & CMIN & DF & CMIN/DF & IFI & TLI & CFI & RMSEA \\
Model E2 & 344.897 & 202 & 1.707 & 0.929 & 0.918 & 0.928 \\
Optimal value & Minimum & - & $<2$ & $>0.9$ & $>0.9$ & $>0.9$ & $<0.1$ \\
\hline
\end{tabular}

\section{Conclusions and Recommendations}

The dimensions of organizational motivation of the "Post-80s" employees include career development, salary and benefits, leadership characteristics, colleague relationship and institutional environment. Organization managers can offer motivation with respect to those five dimensions according to the question items contained in each dimension. The perception of organizational motivation has a positive impact on job satisfaction, organizational commitment and employee engagement and a negative impact on turnover intention of employees. Job satisfaction serves as the complete mediation between the perception of organizational motivation and turnover Intention, while organizational commitment works as the complete mediation between the perception of organizational motivation and employee engagement. Therefore, the improvement of job satisfaction of the "Post-80s" employees can weaken their turnover intention, while the improvement of organizational commitment can facilitate the engagement of the "Post-80s" employees.

The intermediary role of job satisfaction and organizational commitment indicates their key role in the impact of perception of organizational motivation on turnover intention and employee engagement. That is to say, organizations that emphasize and seek for low turnover intention and high employee engagement shall take great efforts to improve job satisfaction and organizational commitment except from organizational motivation; otherwise, the link between Efforts of Organizational Motivation $\rightarrow$ Perception of Organizational Commitment $\rightarrow$ Job Satisfactions and Organizational Commitment $\rightarrow$ Low Turnover Intention and High Employee Engagement will collapse and render the organization's efforts in organizational commitment unfruitful. The author will not elaborate too much on this issues due to the large quantity of existing literature on the improvement of job satisfaction and organizational commitment of the employees. However, the author has made the following recommendations concerning organizational motivation of the "Post-80s" employees.

Career development is the employees' pursuit in realizing their value and improving their living standards and social status. Organizations can offer a good career development prospect for the "Post-80s" employees in the salary raise plan, career development plan and personalized training program.

Salary and benefits are the most direct reward for employees' efforts and are closely related to their daily life. The organizations shall offer competitive salary and benefits that are equal to or better than the market average to the "Post-80s" employees and arrange holidays in accordance with the laws as the "Post-80s" take holidays as important benefits. 
Leadership characteristics reflect the important role of leaders and their behaviors in motivating the employee. Leaders and their behaviors have a lasting impact on the work and career development of employees. It is suggested that the "Post-80s" employees are supervised by capable and amiable leaders. In addition, leaders should take full advantage of emotional motivation and recognize and appreciate the performance of the "Post-80s" employees to enhance their sense of satisfaction and fulfillment; moreover, leaders should offer the employees as much guidance and support as possible in terms of capital, physical and spiritual issues to improve their skills.

Relationship between colleagues reflects the influence of the recessive environment within the organization on for the "Post-80s" employees' psychological perception. Enterprises shall emphasize the harmonious atmosphere and advocate simple and pleasant interpersonal relationship while interpreting and disseminating the corporate culture.

Institutional environment is usually not considered as an essential part of organizational motivation; however, it embodies the concern and introspection of the "Post-80s" employees on the importance of fairness. A fair and reasonable system must be developed by the enterprises and more communication with the employees is necessary for the opinions and recommendations of the "Post-80s" employees to ensure the fairness of processes and procedures.

\section{References}

[1] Li, H. (2008) Influence of Thirty Years of Reform and Opening-Up on Formation of Features of Post 80's. China Youth Study, 11, 89-91.

[2] Peng, G.C. (2008) On Social and Historical Causes of Post 80's Phenomenon in China. China Youth Study, 12, 97-99.

[3] Zhang, B. (2011) The New Thinking on Undergraduate Students' Management in Generation Y. Journal of South China University of Technology (Social Science Edition), 2, 109-111.

[4] Zhou, S. (2009) An Analysis of “the Conception of Profession” of Employees Born after 1980. Management World, 4, 184-185.

[5] Liu, X. (2011) The Mechanism of Organizational Support, Organizational Motivation, Employee Behaviors and R\&D Team Innovation Performance. Ph.D. Thesis, Zhejiang University, Hangzhou.

[6] Locke, E.A. and Latham, G.P. (2004) What Should We Do about Motivation Theory? Six Recommendations for the Twenty-First Century. Academy of Management Review, 29, 388-403.

[7] Steers, R.M., Mowday, R.T. and Shapiro, D.L. (2004) Introduction to Special Topic Forum: The Future of Job Motivation Theory. The Academy of Management Review, 29, 379-387.

[8] Zingheim, P.K. and Schuster, J.R. (2001) Winning the Talent Game: Total Rewards and the Better Job Force Deal. Compensation \& Benefits Management, 17, 23-33.

[9] Turner, S.G., Utley, D.R. and Westbrook, J.D. (1998) Project Managers and Functional Managers: A Case Study of Job Satisfaction in a Matrix Organization. Project Management Journal, 29, 11-19.

[10] Leach, F.J. and Westbrook, J.D. (2000) Motivation and Job Satisfaction in One Government Research and Development Environment. Engineering Management Journal, 12, 3-14. http://dx.doi.org/10.1080/10429247.2000.11415086

[11] Heimovics, R. and Brown, F.G. (1976) Municipal Employee Behavior as and Exchange Process. Midwest Review of Public Administration, 10, 201-215. http://dx.doi.org/10.1177/027507407601000403

[12] Stephen, P.R. (1997) Organizational Behavioral Science. China Renmin University Press, Beijing.

[13] Yao, J. (2009) Study on the Motivational Factors of the "Post-80" Staff. Ph.D. Thesis, Jinan University, Guangzhou.

[14] Hou, C.Y. and Wang, Z.W. (2011) Factor Analysis of Motivational Factors of Knowledge Jobers. Journal of Northwestern Polytechnical University (Social Sciences), 1, 32-36.

[15] Couger, J.D. and Mcintyre, S.C. (1987) Motivation Norms of Knowledge Engineers Compared to Those of Software Engineers. Journal of Management Information Systems, 4, 82-93.

[16] Ling, W.Q., Zhang, Z.C. and Fang, L.L. (2000) The Research on the Structure Model of Chinese Employee's Organizational Commitment. Journal of Management, Science in China, 2, 76-81.

[17] Huo, Y.Y. (2008) Study on the Dimensions and the Related Factors of Employee Engagement. Ph.D. Thesis, Zhejiang University, Hangzhou.

[18] Chen, X.P., Xu, S.Y. and Fan, J.L. (2012) Empirical Methods in Organization and Management Research. Peking University Press, Beijing. 